\title{
Bibliometric Measures and Journal Characteristics of Leading Accounting and Finance Journals
}

\author{
Thomas M. Krueger \\ Texas A\&M University - Kingsville \\ Anne-Marie T. Lelkes \\ Texas A\&M University - Kingsville
}

This study analyzes journal quality metrics and characteristics of leading accounting and finance journals in the Academic Journal Guide. The quality metrics analyzed are Journal Citation Reports (JCR), SCImago Journal Rank (SJR), Source Normalized Impact per Paper (SNIP), and CiteScore. The characteristics analyzed are acceptance rates, issue frequency, journal longevity, number of reviewers, and review time. The findings show that accounting journal SNIP average ratings are higher, finance journal SJR ratings are higher, while the JCR measures are virtually identical. However, CiteScore measures of top-tier accounting journals are significantly higher than those of finance journals. Leading accounting journals are older and have higher acceptance rates. Leading finance journals have more issues, more referees, and longer initial reviews. The journal acceptance rate is the journal characteristic that is the most correlated with measures of journal quality. These findings could be beneficial for accounting and finance junior faculty when working towards promotion and tenure.

Keywords: Journal Quality Metrics, JCR, SNIP, SJR, Citescore, Finance, Accounting

\section{INTRODUCTION}

Authorship in leading academic journals becomes a paramount issue when faculty seeking promotion and tenure put forward their credentials. Submitted dossiers typically include examples of research produced over the preceding years. It is then the job of the administrator to estimate the long-term impact of a faculty member's research stream based on the evidence provided. Assessing the quality of the journals in which the research is published is the primary method used to appraise a faculty member's ability to make a scholarly contribution over his or her career.

Various studies evaluate journal quality across disciplines. For the second language discipline, AlHoorie and Vitta (2018) did a study on the impact of Journal Citation Reports (JCR), SCImago Journal Rank (SJR), Source Normalized Impact per Paper (SNIP), and CiteScore on the quality of the second language research journals. In the nuclear medicine discipline, Ramin and Shirazi (2012) studied the effect of Impact Factor, SJR, and Eigenfactor scores on the quality of nuclear medicine journals. Okagbue et. al. (2018) looked at the impact of Hindawi journals by analyzing CiteScore, editorial board composition, and percentile of Hindawi journals indexed in SCOPUS. 
The focus of this study is in the accounting and finance disciplines. Like Al-Hoorie and Vitta (2018), as a first step in assessing the research, this study evaluates the relative value of research in accounting and finance using the JCR, SJR, SNIP, and CiteScore measures. Additionally, evidence gathered to compare journals in each discipline include journal characteristics which are exogenous to the article itself, such as the acceptance rate, issue frequency, journal longevity, number of reviewers, and review time. Our findings show how these independent variables vary across the accounting and finance disciplines, how they are correlated with journal quality measures, and the extent to which their correlation with journal quality varies across the two disciplines.

The findings in this study could have huge implications for the evaluation of accounting and finance faculty research, departmental scholarship, and university reputations. The department heads in the business disciplines can use this study to make junior faculty aware of what constitutes journal quality to enhance the quality of the junior faculty's research contributions. This study is organized as follows. First, a review of the relevant literature will be provided. Second, the hypotheses and data will be described. Third, the data will be analyzed and the findings provided. Finally, the concluding section summarizes main points of the study and addresses future research opportunities.

\section{LITERATURE REVIEW}

The Association to Advance Collegiate Schools of Business (AACSB) International first introduced standards for intellectual contribution in 1919 (Spritzer and Billings 2005). Over the years, AACSB has updated the research standards to improve research quality, which in turn, enhanced education quality (Spritzer and Billings 2005, The Association to Advance Collegiate Schools of Business 2012). One measure of journal quality is whether the journal requires a blind peer review, with research showing that double-blind peer reviews lead to lower acceptance rates and more critical reviews (Crane 1967, Blank 1991, Snodgrass 2007). The common belief is that the harder it is to get a manuscript published in a journal, the higher the quality of the journal. Another measure of journal quality is the impact factor, which is typically a formula that incorporates the number of citations as one of the variables. Among the more popular measures that research can use to measure impact are Journal Citation Reports (JCR), SCImago Journal Rank (SJR), Source Normalized Impact per Paper (SNIP), and CiteScore.

Clarivate's Web of Science maintains JCR, which was formerly owned by Thomson-Reuters (A1Hoorie and Vitta 2018). SCOPUS maintains SJR, SNIP, and CiteScore (Al-Hoorie and Vitta 2018). Lancho-Barrantes et al. (2010) found that going back three years provides the best measure of journal quality for databases that are broad in scope. JCR is not as strong of a predictor of journal quality as compared to SJR, SNIP, and CiteScore since JCR goes back only two years (Da Silva and Memon 2017, Al-Hoorie and Vitta 2018). SJR goes back three years of citations, but it restricts a journal's ability to inflate its value by limiting self-citations to a maximum of one-third of its issued references (GonzálezPereira et al. 2009, Colledge et al. 2010). SJR factors in prestige over popularity so that two journals of the same popularity may have different ranks based on prestige (Colledge et al. 2010). Thus, a more prestigious journal will have a higher rank than a less prestigious journal. SNIP is more informative if impact and citation potential are to be measured separately (Colledge et al. 2010). CiteScore, a new metric that SCOPUS developed, is like JCR, except it goes back three years unlike two years for JCR (Da Silva and Memon 2017, Al-Hoorie and Vitta 2018). CiteScore is also updated annually (Zijlstra and McCullough 2016).

Furthermore, in the business discipline, there are various listings of quality journals, such as Cabell's Directory of Publishing Opportunities, Association of Business Schools' Academic Journal Guide (AJG), and Australian Business Deans Council's (ABDC) Journal Quality List. Many universities will use one or more of these lists to determine whether a publication is in a quality journal. Krueger (2017) compared journals included in the $A J G$ and the ABDC Journal Quality List to the journals included in Cabell's Directory and found that the $A J G$ have higher standards of quality that does Cabell's Directory.

Various studies have been done regarding quality and impact of business journals. For instance, for finance and information systems journals, Krueger and Shorter (2011) investigated the variation in 
acceptance rates across time. They found that acceptance rates rose between 1994 and 2011 and that double-blind peer reviews have become more frequent (Krueger and Shorter 2011). Krueger, Shorter, and Huff (2012) extended the Krueger and Shorter (2011) study by adding accounting journals and evaluating variations across countries. Additionally, Shorter, Krueger, and Chatelain-Jardon (2012) added marketing journals to the Krueger and Shorter (2011) study and looked at variations across countries. Both studies found that it is more difficult to get articles accepted in the United States than in other countries (Krueger, Shorter, and Huff 2012, Shorter, Krueger, and Chatelain-Jardon 2012). Krueger (2013) extended the Krueger and Shorter (2011) study to evaluate acceptance rates across various finance sub-disciplines in which significant variations were found across those sub-disciplines. Additionally, Shorter (2013) focused solely on information system journals and found that review time, manuscript length, and journal sponsorship affected acceptance rates. Krueger (2014) added management journals to the analysis and found that publication fees have greater impact on acceptance rates than do the review process and number of reviewers. Additionally, publication fees increase the number of significant differences in journal acceptance rates across nations (Krueger 2014). Finally, Krueger and Shorter (2019) extended their 2011 study by comparing the quality of finance and information system journals but for only highquality journals, thus limiting their analysis journals to $A J G$ journals with a JCR value.

Focusing on journals listed in $A J G$, this study evaluates JCR, SJR, SNIP, and CiteScore in addition to the acceptance rates, number of reviewers, review time, and frequency of issue to determine journal quality in the accounting and finance disciplines. Table 1 provides a comparison of JCR, SJR, SNIP, and CiteScore for the accounting and finance journals. Four hypotheses are developed in the next section.

\title{
TABLE 1
}

\section{COMPARISON OF THE FOUR CITATION-BASED QUALITY MEASURES}

\author{
Journal Citation Report (JCR) \\ JCR is the average number of times articles published in the past two years have been cited. For \\ instance, the 2019 JCR would be the number of citations in 2017 and 2018, divided by the number of \\ articles in 2017 and 2018. Citations are drawn from approximately 12,000 journals. \\ SCImago Journal Rank (SJR) \\ SJR is a prestige metric that weights citations based on the journal in which the cited article is \\ published. The number of citations and the importance are used. \\ Source Normalized Impact per Paper (SNIP) \\ SNIP is a contextual metric that weights citations based on the total citations in that subject field. SNIP \\ is a ratio of the average citation count per paper relative to the average citation count in that discipline. \\ It thereby allows citations across subject fields, such as done in this paper. \\ CiteScore \\ Is a Scopus-focused metric that is the number of citations received by a journal in one year to the \\ documents published in the three previous years, divided by the number of documents index in Scopus \\ over the prior three years. Scopus considers all items in a journal, whereas JCR focuses on articles and \\ reviews.
}

\section{HYPOTHESES AND DATA}

One critical issue is whether there are large differences in inferences regarding journal quality across the bibliometric metrics used to measure journal quality. Journal characteristics will also be evaluated to determine whether older journals have different acceptance rates, number of reviewers, review time, and frequency of issue. Krueger (2013) found that there were significant variations with the sub-disciplines of the finance discipline. With that in mind, the variations within the finance and accounting disciplines will be analyzed. 
Four research hypotheses are tested in this study. Stated in null form, the four hypotheses are:

\section{H1: Popular journal quality measures do not vary within discipline.}

If journal quality measures vary within a discipline, it would be possible for authors to pick quality measures that put their research in the best light. The other side of the coin is that administrators may use quality measures putting faculty research in the worst light to drive more and higher quality research. The variation in journal quality factors across the accounting and finance discipline is also examined. Thus, the second research hypothesis stated in the null form is as follows:

\section{H2: Popular journal characteristics vary across disciplines.}

Acceptance rate, when the journal was initially launched, issue frequency, number of reviewers, and length of initial review time are among the myriad of factors authors can contemplate when picking a target journal. As college promotion committees contemplate the quality of a candidate's credentials, they undoubtedly consider performance through the lens of their personal experience. To the extent that there are differences in these journal characteristics, the standard being applied may vary from the reality being faced by a researcher. We assess both the correlation of these factors, which largely are exogenous to the research itself, as well as whether they vary across disciplines. This leads us to an assessment of whether the bibliometric measures are tied to journal characteristics. We assess whether any shift found in one discipline run parallel to changes in journal quality measures experienced in the other discipline. Thus, the third research hypothesis stated in the null form is as follows:

\section{H3: Journal quality measures are independent of journal characteristics.}

The interaction of journal characteristics and journal quality is a key issue facing authors and those that assess the quality of research. Greater quality may be tied to journals with lower acceptance rates or journals that have been in existence for a longer period of time. Editors having more editions may need to include articles with lesser quality to fill up their pages. The number of reviewers and/or time these reviewers spend evaluating articles may also be correlated with journal quality. Thus, the fourth research hypothesis stated in the null form is as follows:

H4: Any interdependence of journal quality measures and journal characteristics is consistently found in all disciplines.

While all the relationships between journal quality and journal characteristics may be important, the focus of this research is whether the interactions vary across disciplines. A given discipline may be more likely to have a relationship between acceptance rates and a given measure of journal quality. In such instances, it is critical for the researchers to consider these journal characteristics in making choices among journals for targeting their manuscripts.

The concept of "leading" or "top-tier" journals is based on the presence of accounting and finance journals listed in the Chartered Association of Business Schools' Academic Journal Guide (AJG) which Krueger (2017) found to be the best criteria for selecting high-quality journals. AJG contains 56 accounting journals and 105 finance journals. Then, all the impact factor scores for JCR, SJR, SNIP, and CiteScore are gathered for each journal along with the acceptance rates, number of reviewers, review

time, and frequency of issue. However, only 21 accounting journals and 34 finance journals contained complete data. The next section provides and analyzes the findings. 


\section{DATA ANALYSIS AND FINDINGS}

\section{Variable Characteristics}

Dependent Bibliometric Measure Characteristics

The first journal-related question faced by researchers and administrators is one of what constitutes journal quality. Quality can be assessed using a variety of metrics, four of which are the focus of this study. Table 2 presents the minimum values, maximum values, median values, and average values for the four bibliographic measures. The left columns include all accounting and finance journals included in the $A J G$. The right columns are limited to the accounting and finance journals for which complete information is available. Complete information is available for 37.5 percent (i.e., $21 \div 56$ ) of top-tier accounting journals and a similar 32.4 percent (i.e., $34 \div 105$ ) of leading finance journals. Despite the sizeable drop in the sample size, the JCR values on the left- and right-hand column are similar for each discipline. For instance, the JCR minimum, maximum, median, and average values never vary by more than 0.10 (i.e., 1.22 v. 1.32). The average JCR value of 1.32 indicates that, on average, all citable articles over the prior two years in leading accounting journals are cited 1.32 times. A slightly lower 1.26 citations are made of citable articles in leading finance journals. For all quality metrics, the t-statistic is used to determine whether accounting and finance journals with complete information are significantly different. This information is displayed at the bottom of each Panel. At the bottom of Table 2's Panel A, one can see that leading accounting and finance journals do not have JCR values which are significantly different. With a low 0.10 t-statistic, they suggest that there is a high degree of similar between the quality of leading accounting and finance journals, using the JCR metric.

TABLE 2

CHARACTERISTICS OF POPULAR BIBLIOMETRIC MEASURES OF LEADING ACCOUNTING AND FINANCE JOURNALS

\begin{tabular}{|c|c|c|c|c|}
\hline & \multicolumn{2}{|c|}{$\begin{array}{l}\text { All Journals in Academic Journal } \\
\text { Guide }\end{array}$} & \multicolumn{2}{|c|}{$A J G$ Journals with Complete Data } \\
\hline & $\begin{array}{l}\text { Accounting } \\
(\mathrm{n}=56)\end{array}$ & $\begin{array}{l}\text { Finance } \\
(\mathrm{n}=105)\end{array}$ & $\begin{array}{l}\text { Accounting } \\
(\mathrm{n}=21)\end{array}$ & $\begin{array}{l}\text { Finance } \\
(\mathrm{n}=34)\end{array}$ \\
\hline \multicolumn{5}{|l|}{ Panel A: JCR } \\
\hline Minimum & 0.07 & 0.32 & 0.07 & 0.30 \\
\hline Maximum & 3.53 & 6.04 & 3.54 & 6.04 \\
\hline Median & 1.22 & 1.13 & 1.32 & 1.26 \\
\hline Average Values & 1.41 & 1.31 & 1.44 & 1.41 \\
\hline \multicolumn{3}{|c|}{ t-statistic ( $p$ value) } & \multicolumn{2}{|l|}{$0.10(0.46)$} \\
\hline \multicolumn{5}{|l|}{ Panel B: SJR } \\
\hline Minimum & 0.10 & 0.10 & 0.21 & 0.25 \\
\hline Maximum & 7.66 & 20.97 & 7.66 & 20.97 \\
\hline Median & 0.52 & 0.52 & 1.07 & 0.97 \\
\hline Average & 1.00 & 1.52 & 1.90 & 2.29 \\
\hline \multicolumn{3}{|c|}{ t-statistic ( $p$ value) } & \multicolumn{2}{|l|}{$-0.41(0.34)$} \\
\hline \multicolumn{5}{|l|}{ Panel C: SNIP } \\
\hline Minimum & 0.10 & 0.01 & 0.34 & 0.38 \\
\hline Maximum & 3.79 & 5.68 & 3.79 & 5.68 \\
\hline Median & 1.07 & 0.84 & 1.61 & 1.16 \\
\hline Mean & 1.18 & 1.08 & 1.74 & 1.47 \\
\hline \multicolumn{3}{|c|}{ t-statistic ( $\mathrm{p}$ value) } & \multicolumn{2}{|l|}{$1.03(0.15)$} \\
\hline
\end{tabular}




\begin{tabular}{|l|l|l|l|l|}
\hline \multicolumn{5}{|l|}{ Panel D: CiteScore } \\
\hline Minimum & 0.14 & 0.01 & 0.39 & 0.38 \\
\hline Maximum & 5.08 & 7.04 & 5.08 & 7.04 \\
\hline Median & 1.24 & 0.80 & 2.16 & 1.36 \\
\hline Mean & 1.45 & 1.18 & 2.28 & 1.66 \\
\hline t-statistic (p value) & & \multicolumn{3}{l|}{$1.74^{*}(0.04)$} \\
\hline
\end{tabular}

The SJR values, which includes consideration of the prestige of the journal in which the citation is found, of all $A J G$-listed accounting journals tend to be lower than the SJR measures of those journal with complete information. For instance, as shown in Panel B of Table 2, minimum accounting SRJ values is 0.10 among all listed journals, which rises to 0.21 for the accounting journals with all data. By comparison, the accounting and finance journal with the highest SJR measure is in the set of journals with all information, resulting in 7.66 and 20.97 values in the respective set of columns. Median values approximately double, while average values tend to go up about seventy percent. However, as shown at the bottom of Panel B, the mean SJR values of accounting and finance journals with complete information are not significantly different.

Similarly, the SNIP value adjusts for discipline-related differences in the number of citations and is shown in Panel C of Table 2. Excluding the "maximum" row, there is a rise in the SNIP values as one scans from all $A J G$ journals, the left side, to those with complete information, the right side. The median and mean SJR values of accounting journals is always higher. Nonetheless, the difference is not significantly different.

The only instance of statistically significant performance exists in Panel D of Table 2, which reports the CiteScore statistics. As shown in the bottom row of Panel D, the difference is statistically significant the 0.05 level. Although the minimums are similar and the finance journals have the higher CiteScore value, accounting journals have significantly higher medians and means. The accounting journal CiteScores median is 59 percent higher.

\section{Independent Journal Characteristics}

Accounting and finance journals are also very similar when it comes to acceptance rate, frequency of issue, year of initial issue, number of reviewers, and duration of initial review. Like Table 2, Table 3 has information for all journals included in the $A J G$ on the left side and journals with complete information on the right side. Also, as with Table 2, minimum, maximum, median, and average values are presented sequentially for these samples of journals. Scanning from the left to right columns, one will find a fair amount of consistency. The one exception to this tendency is that while the maximum acceptance rate among all 105 finance journals in the $A J G$ is 80 percent, the maximum among the 34 finance journals with complete information is 15.5 percent. Nonetheless, there is a 0.25 percent (i.e., $14.0-13.75$ percent) difference in the acceptance rate medians of leading accounting and finance journals. The 1.29 percent (i.e., 15.2 percent - 13.91 percent) difference in mean acceptance rates is not statistically significant.

Frequency of issues range from 1 to 15 among all finance journals in the $A J G$, the latter consisting of monthly issues plus special issues. All listed journals have at least one issue per year. Those journals with complete information have at least two issues per year if they are in the finance realm and three issues per year if they are in the accounting realm. The median number of issues is quarterly. Accounting journals tend to have fewer issues, with an average difference of 1.3 fewer annual issues (i.e., $3.8-5.1$ issues) across all journals in AJG, and 0.9 fewer issues (i.e., 5.1 issues - 6.0 issues) when limiting the sample to only journals with complete information. Although there tend to be more issues of finance journals, the difference is not statistically significant.

Leading accounting journals came into existence between 1926 and 2010, as shown in the first column of Table 3's Panel C. The launch of leading finance journals occurred over a similar period of 1921 to 2012. In terms of medians and mean, accounting journals tend to be slightly older regardless of 
whether one is considering all AJG journals, or only those for which complete information is available. The difference in means for journals with complete information, 5.8 years (i.e., 1985.4 - 1979.6), is significant at the 10 percent level.

TABLE 3 JOURNAL CHARACTERISTICS WITH COMPLETE INFORMATION

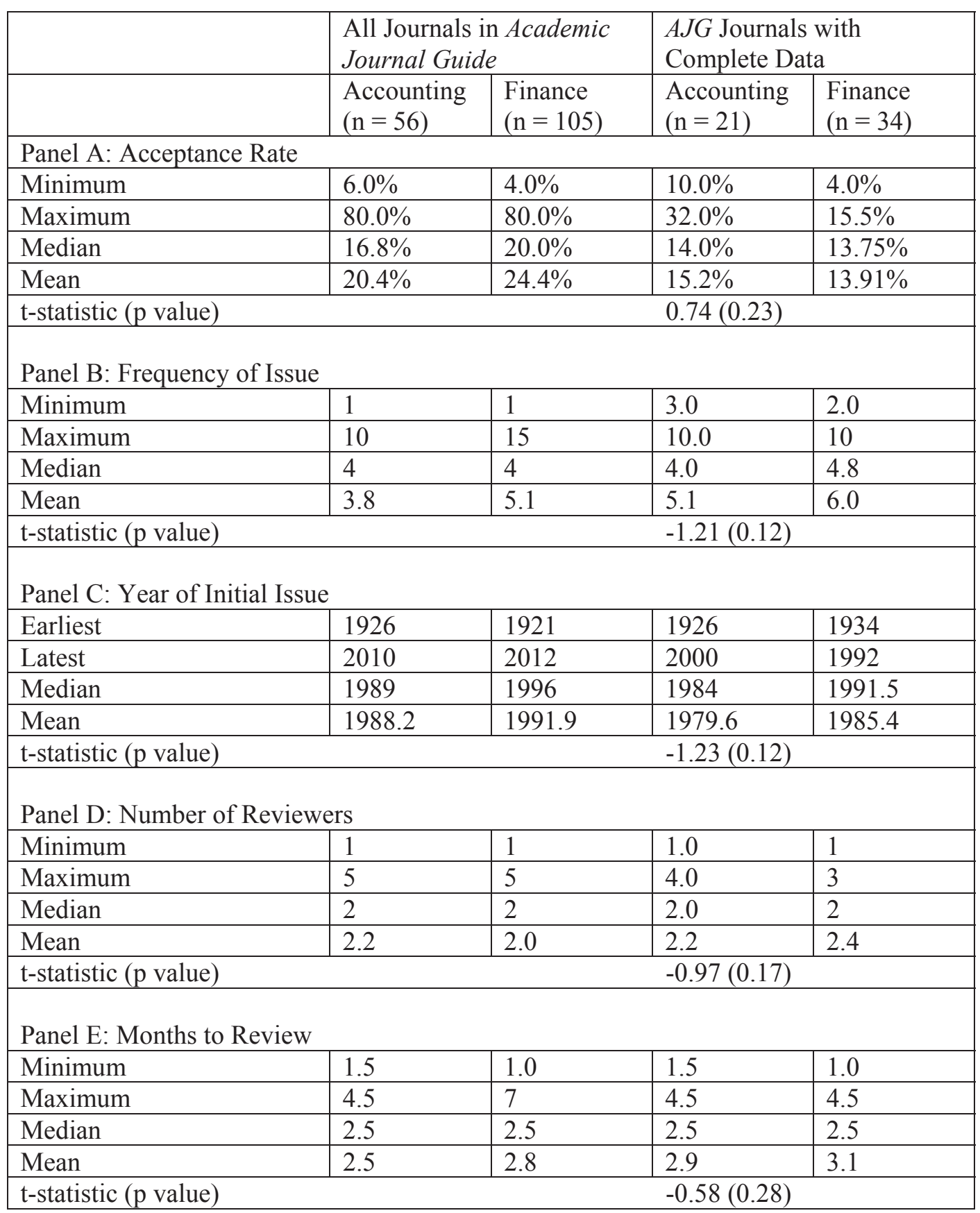

There is much similarity regarding the number of reviewers across accounting and finance journals, as reported in Panel D of Table 3. In fact, the minimums and medians are identical whether one is 
considering all $A J G$ listed journals or those with complete information. On average, accounting and finance journals use about 2.3 reviewers, with almost no difference; resulting in the lowest $\mathrm{p}$ value.

The duration of the initial reviews is also similar, as shown in Panel E of Table 3. Although the time to review ranges from one to seven months across all $A J G$-listed finance journals, limitation of the sample to those journals reduces the length from seven to four and one-half months. The medians are identical, with the means being within one third of a month, or under 10 days. Hence, it is not surprising that there is no statistical significance between accounting and finance journals regarding this exogenous variable. In summary, there is no tendency of accounting journals to vary from finance journals on these factors.

\section{Quality Metric Correlation}

Correlation among the chosen bibliometric measures is quite high, as shown by the high values in Table 4. The lowest Pearson correlation value among accounting journals, which are in Panel A, is 0.86 which occurs three times. The highest correlation is 0.97 found between CiteScore and SNIP dependent variables.

TABLE 4

\section{PEARSON PRODUCT-MOMENT CORRELATION OF BIBLIOMETRIC MEASURES}

\begin{tabular}{|l|l|l|l|}
\hline & SJR & SNIP & CiteScore \\
\hline Panel A: Accounting Journals \\
\hline JCR & 0.86 & 0.90 & 0.93 \\
\hline SJR & & 0.86 & 0.86 \\
\hline SNIP & & & 0.97 \\
\hline Panel B: Finance Journals & 0.92 & 0.96 & 0.96 \\
\hline JCR & & 0.93 & 0.92 \\
\hline SJR & & & 0.98 \\
\hline SNIP & & & \\
\hline
\end{tabular}

Bibliometric measure correlation is even higher among finance journals, which is shown in Panel B of Table 4. The lowest correlation is the 0.92 level for the correlation of the SJR and CiteScore metrics. Once again, the SNIP and CiteScore measures have the highest values, registering a value of 0.98, which indicates that they are nearly identical.

These findings support the null form of H1. Within each discipline, there is high correlation among the bibliometric measures. Despite the rhetoric regarding which bibliometric measure is more valuable, they present similar indications regarding journal quality. Although we would expect high quality ratings among journals in the $A J G$, such a high level of agreement across bibliometric measures is somewhat surprising. 


\section{Journal Characteristic Correlation}

Pearson product-movement correlations of the independent variables are reported in Table 5. In contrast to the dependent measures of journal quality, there is low correlation among the independent journal characteristics. Among accounting journals, Pearson correlation coefficients range from 0.30 to 0.35 , while among finance journals, journal demographics range from 0.35 to -0.31 . Squaring the highest absolute values, which are 0.35 and -0.35 , results in a coefficient of determination of 0.12 , which indicates that 88 percent of an independent variable's variation arises from other factors. This finding conflicts with $\mathrm{H} 1$.

Nonetheless, some insight to journal demographics is possible by focusing on instances with higher correlation coefficients. For instance, the positive 0.30 correlation between accounting journal acceptance rate and date of issue indicates that newer journals have a higher acceptance rate. The negative 0.35 correlation between acceptance rate and number of reviewers suggests that accounting journal acceptance rates decline as the number of reviewers increases. The negative 0.26 correlation between date of initial issue and issues per year suggests that newer journals have fewer issues per year. Perhaps newer accounting journals are having a tougher time attracting submissions. A catch-22 aspect of this relationship is that having fewer issues, assuming an equal number of articles per journal, is likely to reduce the number of times a journal is found among citations. Considering the other correlation above 0.25 in Panel A, it appears that newer journals have a propensity to use more reviewers.

TABLE 5

\section{CORRELATION OF VARIOUS JOURNAL CHARACTERISTICS}

\begin{tabular}{|c|c|c|c|c|}
\hline & $\begin{array}{l}\text { Date of } \\
\text { Initial Issue }\end{array}$ & Issues Per Year & $\begin{array}{l}\text { Length of time for } \\
\text { Initial Review } \\
\text { (months) }\end{array}$ & $\begin{array}{l}\text { Number of } \\
\text { Reviewers }\end{array}$ \\
\hline \multicolumn{5}{|c|}{ Panel A: Accounting Journals } \\
\hline Acceptance Rate & 0.30 & -0.07 & -.0 .35 & 0.06 \\
\hline Date of Initial Issue & & -0.26 & -0.05 & 0.26 \\
\hline Issues Per Year & & & 0.17 & -0.18 \\
\hline $\begin{array}{l}\text { Length of time for } \\
\text { Initial Review (months) }\end{array}$ & & & & -0.08 \\
\hline \multicolumn{5}{|l|}{ Panel B: Finance Journals } \\
\hline Acceptance Rate & 0.18 & 0.16 & 0.22 & 0.13 \\
\hline Date of Initial Issue & & 0.02 & 0.04 & -0.31 \\
\hline Issues Per Year & & & 0.10 & -0.11 \\
\hline $\begin{array}{l}\text { Length of time for } \\
\text { Initial Review (months) }\end{array}$ & & & & 0.35 \\
\hline
\end{tabular}

The highest correlation among chosen characteristics of finance journals exists between the number of reviewers and time to review variables. The Pearson correlation coefficient for this combination is found in the bottom right cell in Panel B of Table 5. It is logical that as the number of reviewers rises the time required to complete a review also goes up. The other correlation with an absolute value above 0.25 is the negative correlation between date of initial issues and time to review. Unlike the situation found among top-tier accounting journals, newer finance journals have a shorter review time. A shorter review time could be used to attract authors. However, for both accounting and finance journals, there is a limited amount of collinearity, thus allowing for the inclusion of all five journal characteristics in the regression models. 


\section{Journal Quality Estimates Based on Journal-Related Variables}

Relationship between Journal Characteristics and Measures of Journal Quality

Multiple regression equations are estimated in order to evaluate the relationship between journal quality and journal characteristics. Journal quality served as the dependent variable, while the independent variables consisted of the five journal characteristics studied in this analysis. JCR, SJR, SNIP and CiteScore are considered sequentially in this assessment related to $\mathrm{H} 3$, for which the null hypothesis assumes that there is no relationship between journal quality and journal characteristics. The regression equation is exhibited below.

Journal Quality $=$

$$
\alpha+b_{1} \text { AcceptanceRate }+b_{2} \text { Launch }+b_{3} \text { Frequency }+b_{4} \text { Reviewers }+b_{5} \text { ReviewTime }
$$

where: AcceptanceRate $=$ reported acceptance rate

Launch = Initial year of journal publication

Frequency $=$ number of issues each year

Reviewers $=$ Number of reviewers, as reported by editor

ReviewTime $=$ Duration of average initial review

All independent variables are reported in Cabell's Directory of Publishing Opportunities in Accounting and Cabell's Directory of Publishing Opportunities in Finance. In cases where the journal reports a range of acceptance rates, reviewers, and review times, the mean value are used as the given journal measure for the independent variable.

Findings for the four different journal quality factors are exhibited in Table 6's four panels, with the accounting regression equation appearing first and the finance journal regression equation appearing second in each panel. In Panel A, the finance journals' multiple regression equation has an F-statistic of 3.01, which is significant at the 0.05 level and explains 23.3 percent of the variation in journal quality. Finance journal acceptance rate and issues per year are significant at the 0.01 and 0.05 levels, respectively. The signs of the regression coefficients indicate that journal quality as measured by JCR declines with higher acceptance rates, but rises as the number of issues per year rises. The former is not surprising, because it is logical that more prestigious journals would have lower acceptance rates. The positive correlation between JCR value and issues per year may be a consequence of a journal with few issues per year having fewer chances for citation by later articles appearing in the same journal. This finding would be consistent with a journal with a limited number of annual editions not being closely monitored. Although the model is not statistically significant when applied to accounting journals, the initial time to review is significant at the 0.05 level. The positive coefficient term suggests that as more time is spent in the review process journal quality increases.

Shifting the focus to SJR, one sees that the five independent variables explain a lower proportion of the differences in journal quality. The adjusted R2 falls from an average value of 19.3 percent (i.e., ( 0.153 $+0.233) / 2$ ) to 14.6 percent (i.e., $(0.108+0.183) / 2)$. Neither regression equation is significant at the 0.05 level. However, the importance of acceptance rate in explaining variation in finance journal's SJR measures is significant at the 0.05 level. Similar results exist for the SNIP variable, with the highly significant acceptance rate term driving regression model significance to the 0.05 level among finance journals.

Considering the significant discipline-related dummy variable reported in the next section, the most interesting contrast of Table 6 can be found in Panel D. There one can find that the finance regression equation is again significant at the 0.05 level, with both the acceptance rate and issues per year being significant at the 0.01 and 0.05 levels, respectively. It, therefore, parallels the JCR findings shown in Panel A of Table 6. By contrast, no significance is observed in the regression equation based on accounting journal information. Hence, the statistically significant dummy variable found on Panel D of Table 7 arises from the interaction of finance journal quality metrics and journal characteristics. 
Discipline-Based Variation in the Relationship Between Journal Characteristics and Measures of Journal Quality

A discipline-related independent variable is added to capture any discipline-based variation in the relationship between journal characteristics and the measures of journal quality. For instance, in Panel C of Table 6, one finds that the SNIP regression equation coefficients on acceptance rate are negative for accounting journals and finance journals. Yet, only finance journals have a regression coefficient that is significant. This extension of the prior regression model detects whether the explanatory power of the accounting journals and finance journals are significantly different. The following multiple regression equation is used to assess the relative impact of the various journal characteristics, including discipline covered, on each examined journal quality measures

\section{TABLE 6 \\ REGRESSION RESULTS FOR ACCOUNTING AND FINANCE JOURNALS INDEPENDENTLY}

\begin{tabular}{|c|c|c|c|c|c|c|c|c|}
\hline Discipline & $\begin{array}{l}\text { F- } \\
\text { statistic }\end{array}$ & Significance & $\begin{array}{l}\text { Adjusted } \\
\text { R2 }\end{array}$ & $\begin{array}{l}\text { Acceptance } \\
\text { Rate }\end{array}$ & Launch & Frequency & $\begin{array}{l}\text { Review } \\
\text { Time }\end{array}$ & Reviewers \\
\hline \multicolumn{9}{|l|}{ Panel A: JCR } \\
\hline Accounting & 1.721 & 0.194 & 0.153 & $\begin{array}{l}0.730 \\
(0.843)\end{array}$ & $\begin{array}{l}-0.010 \\
(0.336)\end{array}$ & $\begin{array}{l}0.246 \\
(0.168)\end{array}$ & $\begin{array}{l}0.577^{*} \\
(0.044)\end{array}$ & $\begin{array}{l}-0.179 \\
(0.195)\end{array}$ \\
\hline Finance & 3.01 & $0.027 *$ & 0.233 & $\begin{array}{l}-7.159 * * \\
(-0.010)\end{array}$ & $\begin{array}{l}-0.004 \\
(0.708)\end{array}$ & $\begin{array}{l}0.110^{*} \\
(0.045)\end{array}$ & $\begin{array}{l}-0.147 \\
(0.259)\end{array}$ & $\begin{array}{l}0.334 \\
(0.092)\end{array}$ \\
\hline \multicolumn{9}{|l|}{ Panel B: SJR } \\
\hline Accounting & 1.48 & 0.252 & 0.108 & $\begin{array}{l}2.104 \\
(0.827)\end{array}$ & $\begin{array}{l}-0.026 \\
(0.359)\end{array}$ & $\begin{array}{l}0.810 \\
(0.827)\end{array}$ & $\begin{array}{l}1.463 \\
(0.051)\end{array}$ & $\begin{array}{l}-0.701 \\
(0.060)\end{array}$ \\
\hline Finance & 2.48 & 0.056 & 0.183 & $\begin{array}{l}-21.889^{*} \\
(0.0376)\end{array}$ & $\begin{array}{l}-0.037 \\
(0.366)\end{array}$ & $\begin{array}{l}0.327 \\
(0.121)\end{array}$ & $\begin{array}{l}-0.772 \\
(0.130)\end{array}$ & $\begin{array}{l}0.651 \\
(0.391)\end{array}$ \\
\hline \multicolumn{9}{|c|}{ Panel C: SNIP } \\
\hline Accounting & 0.980 & 0.462 & -0.005 & $\begin{array}{l}-1.185 \\
(0.799) \\
\end{array}$ & $\begin{array}{l}-0.009 \\
(0.493) \\
\end{array}$ & $\begin{array}{l}0.194 \\
(0.379) \\
\end{array}$ & $\begin{array}{l}0.548 \\
(0.120) \\
\end{array}$ & $\begin{array}{l}-0.209 \\
(0.227)\end{array}$ \\
\hline Finance & 2.724 & $0.034 *$ & 0.171 & $\begin{array}{l}-7.023 * * \\
(0.009)\end{array}$ & $\begin{array}{l}-0.001 \\
(0.926)\end{array}$ & $\begin{array}{l}0.094 \\
(0.078) \\
\end{array}$ & $\begin{array}{l}-0.158 \\
(0.211) \\
\end{array}$ & $\begin{array}{l}0.295 \\
(0.125) \\
\end{array}$ \\
\hline \multicolumn{9}{|c|}{ Panel D: CiteScore } \\
\hline Accounting & 0.950 & 0.478 & -0.013 & $\begin{array}{l}-1.754 \\
(0.788)\end{array}$ & $\begin{array}{l}-0.010 \\
(0.610)\end{array}$ & $\begin{array}{l}0.355 \\
(0.253) \\
\end{array}$ & $\begin{array}{l}0.737 \\
(0.133) \\
\end{array}$ & $\begin{array}{l}-0.293 \\
(0.226) \\
\end{array}$ \\
\hline Finance & 2.720 & $0.040 *$ & 0.207 & $\begin{array}{l}-9.593 * * \\
(0.007)\end{array}$ & $\begin{array}{l}-0.001 \\
(0.969)\end{array}$ & $\begin{array}{l}0.142^{*} \\
(0.044)\end{array}$ & $\begin{array}{l}-0.166 \\
(0.316)\end{array}$ & $\begin{array}{l}0.234 \\
(0.347)\end{array}$ \\
\hline
\end{tabular}

Journal Quality

$=\alpha+b_{1}$ Discipline $+b_{2}$ AcceptanceRate $+b_{3}$ Launch $+b_{4}$ Frequency $+b_{5}$ Reviewers $+b_{5}$ ReviewTime

where: Discipline $=$ dummy variable; 0 for Accounting journals, 1 for finance journal

AcceptanceRate $=$ reported acceptance rate

Launch = Initial year of journal publication

Frequency $=$ number of issues each year

Reviewers $=$ Number of reviewers

ReviewTime $=$ Duration of average review

A significant dummy variable coefficient, $b_{1}$, would be an indication that journal quality measures vary by discipline across the account and finance genre. Separate multiple regression equations are run for each of the four studied journal quality metrics, with findings displayed in the four columns found in 
Table 7. Model statistics are reported in Panel A, Independent variable coefficients are reported in Panel B.

Multiple regression model F-statistics and related values of statistical significance are reported in the first column of Table 7. Across the four measures of journal quality, the F-statistic is close, being in the 2.280 to 2.590 range. In three instances the F-statistic is significant at the 0.05 level. Only SNIP is not statistically significant at the 0.05 level. However, with a 0.051 level the regression is almost statistically significant at the 0.05 level. The independent variables explain between 12 percent and 18 percent of the variation in journal quality.

TABLE 7 MULTIPLE REGRESSION RESULTS

\begin{tabular}{|c|c|c|c|c|}
\hline & JCR & SJR & SNIP & CiteScore \\
\hline \multicolumn{5}{|c|}{ Panel A: Model Statistics } \\
\hline F-statistic & $2.590^{*}$ & $2.38 *$ & 2.280 & $2.933^{*}$ \\
\hline F Significance & 0.029 & 0.042 & 0.051 & 0.016 \\
\hline Adjusted R2 & 0.150 & 0.133 & .125 & 0.177 \\
\hline \multicolumn{5}{|c|}{ Panel B: Independent Variables } \\
\hline Dummy Variable & $\begin{array}{l}-0.175 \\
(0.504)\end{array}$ & $\begin{array}{l}0.194 \\
(0.834)\end{array}$ & $\begin{array}{l}-0.406 \\
(.136)\end{array}$ & $\begin{array}{l}-0.818^{*} \\
(0.025)\end{array}$ \\
\hline AcceptanceRate & $\begin{array}{l}-6.061 * * \\
(0.005)\end{array}$ & $\begin{array}{l}-18.199^{*} \\
(0.016)\end{array}$ & $\begin{array}{l}-6.320 * * \\
(0.005)\end{array}$ & $\begin{array}{l}-8.687 * * \\
(0.003)\end{array}$ \\
\hline Launch & $\begin{array}{l}-0.008 \\
(0.316)\end{array}$ & $\begin{array}{l}-0.035 \\
(0.196)\end{array}$ & $\begin{array}{l}-0.005 \\
(0.519)\end{array}$ & $\begin{array}{l}-0.005 \\
(0.648)\end{array}$ \\
\hline Frequency & $\begin{array}{l}0.095 * * \\
(0.042)\end{array}$ & $\begin{array}{l}0.253 \\
(0.124)\end{array}$ & $\begin{array}{l}0.068 \\
(0.151)\end{array}$ & $\begin{array}{l}0.119 \\
(0.060)\end{array}$ \\
\hline Reviewers & $\begin{array}{l}0.136 \\
(0.336)\end{array}$ & $\begin{array}{l}0.104 \\
(0.836)\end{array}$ & $\begin{array}{l}0.098 \\
(0.504)\end{array}$ & $\begin{array}{l}0.025 \\
(0.895)\end{array}$ \\
\hline ReviewTime & $\begin{array}{l}-0.029 \\
(0.768)\end{array}$ & $\begin{array}{l}-0.479 \\
(0.179)\end{array}$ & $\begin{array}{l}-0.049 \\
(0.632)\end{array}$ & $\begin{array}{l}-0.044 \\
(0.744)\end{array}$ \\
\hline
\end{tabular}

Insight to the importance of the independent variables for each of the journal quality measures is given in Panel B of Table 7. Journal acceptance rate and annual issue frequency are both significant at the 0.05 level when the JCR quality metric serves as the independent variable, as exhibited in the first column of Table 7. The negative sign on acceptance rate suggests that as the acceptance rate increases the JCR measure of journal quality declines. This finding is consistent with expectations that quality journals are more selective and essentially becomes a self-fulfilling prophesy. Lower acceptance rates undoubtedly result in lesser quality articles being rejected, resulting in remaining articles being are more likely to be cited. Less logical is the positive coefficient on the annual frequency of issue variable. A higher frequency may attract more authors to its pages, resulting in higher citations. Whatever the cause, scanning across the frequency row reveals that this variable is only significant when the JCR value serves as the dependent variable.

Only the acceptance rate is a significant factor when SJR serves as a measure of journal quality. However, acceptance rate is significant at the 0.05 level. As with all journal metrics, the coefficient on the acceptance rate term is negative meaning that even among top-tier accounting and finance journals lesser quality journals have higher acceptance rates. In like manner, the SNIP variable is significantly related to the acceptance rate and again one finds that higher quality journals have lower acceptance rates.

CiteScore-related findings are shown on the right side of Table 7, where we find a significant difference coefficient in the dummy variable row. The negative value indicates that finance journals, for which the dummy variable is 1 , are less likely to have high CiteScores. This finding is consistent with the 
0.62 higher average score of Accounting journals, which is reported in Panel D of Table 2. As with other journal quality metrics, acceptance rates are statistically significant. One would expect journals with high CiteScores to be in the accounting arena and have relatively low acceptance rates. Annual frequency of issue is significant at the 0.05 level, with a positive coefficient implying that higher quality journals publish more frequently, which is in accordance with the JCR findings found in the first column.

\section{CONCLUSION}

Important decisions draw upon information from a wide variety of sources. Perhaps the most important decisions in academia concern promotion and tenure. A key input to these decisions is the quality of research produced by the candidate. Without a means to effectively gauge the long-term value of faculty research, administrators often turn to journal rankings. This research investigated the information supplied by four popular bibliometric measures: the JCR, SJR, SNIP, and CiteScore. We examined the extent to which journal characteristics are tied to these bibliometric measures. We also studied the robustness of the relationships observed across the accounting and finance disciplines.

To lead this research, we examined four research hypotheses. These hypotheses are restated below, with information regarding how the present research answered these research questions.

\section{H1: Popular journal quality measures do not vary within discipline.}

Except for the CiteScore metric, journal quality metrics of leading accounting and finance journals are similar. Accounting journal SNIP average ratings are higher, finance journal SJR ratings are higher, while the JCR measures are virtually identical. None of these measures are significantly different. However, CiteScore measures of top-tier accounting journals are significantly higher than the CiteScore ratings of finance journals. Furthermore, the individual journal quality metrics are highly correlated. This finding is very important, because the faculty development committee and the retention, promotion, and tenure committee of business schools often consist of members from multiple disciplines. There is very little discipline-related systematic bias in the perception of journal quality which could distort the overall perception of faculty research.

\section{H2: Popular journal characteristics vary across disciplines.}

No significant difference is observed across commonly considered journal characteristics. Leading accounting journals tend to be slightly older and have a slightly higher acceptance rate. By comparison, leading finance journals tend to have more issues, be reviewed by more referees, who take more time in the initial review stage. Yet, none of the journal characteristics are significantly different. Furthermore, the correlation of journal characteristics is relatively low. Hence, it appears as though authors from these two disciplines face a somewhat consistent set of challenges when attempting to get published.

\section{H3: Journal quality measures are independent of journal characteristics.}

As one might expect, journal acceptance rate is the journal characteristic found to be the most likely to be correlated with various measures of journal quality. The frequency of issue is found to be significantly related to journal quality twice, while time to review is found to be significant once. Neither the date of initial publication nor the number of reviewers is found to be significantly related to journal quality in either discipline. Independently, each quality measure is found to be related to at least one finance journal characteristic, while the quality measures are found to be significantly related the independent accounting journal characteristics once.

H4: Any interdependence of journal quality measures and journal characteristics is consistently found in all disciplines. 
The perceived differences observed when multiple regression equations are run for the accounting and finance journals independently does not carry over to the multiple regression where a dummy variable is used to designate the discipline of a specific journal. In this direct test of the importance of journal discipline, the dummy variable tied to journal discipline is only significant for the CiteScore measure. Hence, accounting or finance researchers are not necessarily at an advantage in terms of the quality measure of their journals after taking into consideration the other studied independent variables.

Further research could assess the extent to which these relationships vary across national boundaries. Such research could determine the consistence in bibliometric measures, journal characteristics, and the relationship between these in multiple countries. Another venue for investigation is the trends that exist in bibliometric measures across the globe. Are journals in some countries replacing journals in other countries as the authoritative source of information? Are there trends in relevant journal characteristics? As scholarship is evaluated on a global basis and the meaning of scholarship changes, answers to these questions have a critical impact on the assessment of authors and their institutions.

\section{REFERENCES}

Al-Hoorie, A. H., \& Vitta. J.P. (2018, April). The seven sins of L2 research: A review of 30 journals' statistical quality and their CiteScore, SJR, SNIP, JCR Impact Factors. Language Teaching Research, 1-18.

Blank, R. (1991). The effects of double-blind versus single-blind reviewing: Experimental evidence from The American Economic Review. The American Economic Review, 81(5), 1041-1067.

Colledge, L., de Moya-Anegón, F., Guerrero-Bote, V. P.., López-Illescas, C., \& Moed, H.F. (2010). SJR and SNIP: two new journal metrics in Elsevier's Scopus. Insights, 23(3), 215-221.

Crane, D. (1967). The gatekeepers of science: Some factors affecting the selection of articles for scientific journals. The American Sociologist, 2(4), 195-201.

Da Silva, J. A. T., \& Memon, A.R. (2017). CiteScore: A cite for sore eyes, or a valuable, transparent metric? Scientometrics, 111(1), 553-556.

González-Pereira, B., Guerrero-Bote, V. P., \& Moya-Anegón, F. (2009). The SJR indicator: A new indicator of journals' scientific prestige. Retrieved July 4, 2019, from http://arxiv.org/ftp/arxiv/papers/0912/0912.4141.pdf

Krueger, T. M. (2013). Acceptance rates of finance journals dedicated to various areas: Impact of review type and reviewer number. Mustang Journal of Accounting and Finance, 3, 65-88.

Krueger, T. M. (2014). Paying for acceptance? A study of academic management journals. Mustang Journal of Business and Ethics, 6, 31-46.

Krueger, T. M. (2017). A comparison of CABS' Academic Journal Guide, Australian Business Deans Council's list, and Cabell's Directory of Publishing Opportunities in finance. Journal of Financial Education, 43(2), 313-338.

Krueger, T. M., \& Shorter, J.D. (2011). Variation in scholarly journal review processes and acceptance rates across time and disciplines. Southwestern Business Administration Journal, 11(2), 71-112.

Krueger, T. M., \& Shorter, J.D. (2019). A comparison of high-quality finance journals and high-quality information systems journals. Journal of Higher Education Theory and Practice, 19(1), 95-104.

Krueger, T. M., J. D. Shorter, \& Huff, K. (2012). International differences in business journal acceptance rates across business disciplines. International Journal of Business and Social Science, 3(3), 1-16.

Lancho-Barrantes, B. S., Guerrero-Bote, V. P., \& Moya-Anegón, F. (2010). What lies behind the averages and significance of citation indicators in different disciplines? Journal of Information Science, 36(3), 371-382.

Okagbue, H. I., Atayero, A. A., Adamu, M. O., Bishop, S. A., Oguntunde, P. E., \& Opanuga, A.A. (2018, August). Exploration of editorial board composition, CiteScore and percentiles of Hindawi journals indexed in Scopus. Data in Brief, 743-752. 
Ramin, S., \& Shirazi, A.S. (2012). Comparison between Impact factor, SCImago journal rank indicator and Eigenfactor score of nuclear medicine journals. Nuclear Medicine Review, 15(2), 132-136.

Shorter, J. D. (2013). Distinctions in academic journal review processes and acceptance rates across time \& how time to review, manuscript length, and sponsorship effect periodical acceptance rates in the information systems disciplines. Journal of Information Systems Technology \& Planning, 5(15), 87-111.

Shorter, J. D., Krueger, T. M., \& Chatelain-Jardon, R. (2012). Discipline, nation, and time based differences in business journal acceptance rates and review processes. Journal of International Business Management \& Research, 3(7), 147-163.

Snodgrass, R. T. (2007). Editorial: Single-versus double-blind reviewing. ACM Transactions and Database Systems, 32(1), 1-29.

Spitzer, A. D., \& Billings, C.D. (2005). Faculty intellectual contributions under the new AACSB international accreditation standards. Journal of Business and Behavioral Research, 13(1), 46-64.

The Association to Advance Collegiate Schools of Business (AACSB). (2012). Impact of research: A guide for business schools. Tampa, FL: AACSB International.

Zijlstra, H., \& McCullough, R. (2016, December 12). CiteScore: a new metric to help you choose the right journal. Elsevier. Retrieved July 4, 2019, from https://www.elsevier.com/authorsupdate/story/impact-metrics/citescore-a-new-metric-to-help-you-choose-the-right-journal 